\title{
FIELD APPLICATION FOR EXPERIMENTAL INACTIVATED MULTIVALENT $P$. multocida AND AVIAN INFLUENZA (H9N2) VACCINE IN POULTRY
}

\author{
Selim S. Salama ${ }^{1 *}$, Heba A. Abdelhady², Lamiaa Atia ${ }^{3}$
}

${ }^{1}$ Central Laboratory for Evaluation of veterinary Biologics (CLEVB), Cairo, Egypt, ${ }^{2}$ Animal Health Research Institute (AHRI), Alexandria branch, Alexandria, Egypt, ${ }^{3}$ Animal Health Research Institute (AHRI), Banha branch, Qalyubia, Egypt

*Corresponding author, E-mail: selimsalama2000@yahoo.com

\begin{abstract}
Fowl cholera (FC) and Avian Influenza (AI) are two of the major economically important respiratory and septicaemic disease of poultry in Egypt and allover the world. A field trails was conducted to evaluate the immunogenicity of an experimentally multivalent inactivated Fowl cholera (P. multocida) and Avian Influenza (H9N2) vaccine. The In this study a combined inactivated Montanide ISA fowl cholera and AI vaccine was prepared then the immunization potency and protective efficacy were evaluated through experimental application on different poultry breeds including broiler breeder, broiler and turkey flocks. The peak of humeral immune response against $P$. multocida as measured by ELISA was at the 5th week post vaccination and at 3rd week post boostering all over the used poultry flocks. At the same time, Al immune response as measured by $\mathrm{HI}$ reached the peak at the $6^{\text {th }}$ week post vaccination and at $2^{\text {nd }}$ week post boostering. $R e-$ garding the challenge test, the protection levels were $76.6,70$ and $80 \%$ and $90,86.6$ and 93.3\% against $P$. multocida while protection levels were $83.3,80$ and $86.6 \%$ and $93.3,90$ and $96.6 \%$ against $A \mathrm{I}$ virus after challenge with the used virulent strains post single and booster dose respectively. In conclusion the combined prepared fowl cholera and Al vaccine succeeded in eliciting protective antibody titres and full protection against both fowl cholera and $\mathrm{Al}$ diseases.
\end{abstract}

Key words: Pasteurella multocida; AI; vaccine; ELISA; PHA; HI; challenge test

\section{Introduction}

Fowl cholera (1) and AI (2) are two of the major economically important respiratory and septicaemic diseases of poultry in Egypt and allover the world. They are highly contagious diseases causing devasting economic losses to the poultry industry through death, weight loss and condemnation of carcasses worldwide.
Fowl Cholera caused by $P$. multocida which belongs to the family Pasteurellaceae and classified into five groups based on capsular antigens and into 16 serotypes based on LPS antigens (3). It occurs sporadically or enzootically as peracute, acute or chronic form all over the world (4). Mortality may range from only few percent to nearly $100 \%$ and recovered birds may remain as carriers even after 9 weeks after infection (1). 
Avian influenza (AI) is an infectious respiratory disease of birds caused by avian influenza type A viruses that are members of the family Orthomyxoviridae (5). The H9N2 avian influenza virus (AIV) was reported to be of low pathogenicity in chickens $(6,7)$ causing minimal clinical signs other than a slight drop in egg production but greatly has immunosuppressive effect (8) confirmed that the control of H9N2 viruses in poultry is important.

Combination of bacterial and viral vaccines which contain multiple antigens has many benefits for the manufacturer as it reduce production costs, for the administrator as it save time, effort and simplify the immunization schedule and for the animals as it minimize stress of multiple vaccinations (9).

The aim of this study is to evaluate the usage of a combined vaccine against FC and AI diseases prepared with Montanide ISA 206 as adjuvant under field condition.

\section{Materials and methods}

\section{Strains used}

a-Pasteurella multocida serotypes (1, 3, and 4): obtained from the Strain Bank, Central Laboratory for Evaluation of Veterinary Biologics (CLEVB), Cairo, Egypt.

$b$ - AI H9N2: isolated in the Central Laboratory for Evaluation of Veterinary Biologics (CLEVB), yearling 2015, Cairo, Egypt.

\section{Vaccine Preparation}

a- Preparation of inactivated Pasteurella multocida antigenic phase

A virulent local strains of $P$. multocida Serotypes 1, 3, 4 and D2 were propagated in brain heart infusion broth (BHI) at $37^{\circ} \mathrm{C}$ for 24 hours to obtain a dense culture containing approximately $2 \times 10^{9} \mathrm{CFU}$ of each strain. After inactivation by addition of $0.1 \%$ formalin, each culture was tested for purity, safety and sterility as mentioned by (10). Finally, cultures were equally mixed together then preserved with $0.01 \%$ of thiomersal and stored at $4 \mathrm{C}^{\circ}$ until use.
$b$-Preparation of inactivated AI antigenic phase

Propagation and titration of AI H9N2 that locally isolated were done in SPF 9 -10 day old ECE according to (11) and (12). Its titer was $10^{9}$ $\mathrm{EID}_{50} / \mathrm{ml}$. Inactivation of AI virus was carried out using binary ethelenamine $0.1 \mathrm{M}$ with final concentration $0.01 \mathrm{M}$. Inactivation and testing of inactivation was done according to (13).

$c$ - Preparation of combined inactivated FC and AI vaccine by using ISA 206

A combined vaccine of $P$. multocida and AI was prepared water in oil in water emulsion by mixing equal volumes of the inactivated $P$. multocida antigenic phase and inactivated $\mathrm{AI}$ antigenic phase to form an aqueous phase and immersed in equal volume of Montanide ISA 206 oil adjuvant (SEPPIC, cosmetics, pharmacy division, Paris, France).

\section{Quality control of the prepared vaccine}

The vaccine was tested for sterility and safety following the standard international protocol as described by OIE (14) before the usage in the field trial.

\section{Experimental design}

A separate broiler breeder, broiler and turkey flock houses were used through the experimental work of this study. Birds were vaccinated I/M at the age of six weeks, 2 weeks and 4 weeks respectively with $0.5 \mathrm{ml} /$ bird with the prepared combined vaccine. Random 60 birds from each group were transferred to a specific isolator to be challenged 3 weeks post first vaccination. A group of the rest birds of the different flocks were then received booster dose and 3 weeks apart challenge test were done. Also a group of the broiler were kept to continue in a special house to complete the period of experiment. A group of bird per each flock were kept as non-vaccinated control group. Random serum samples were collected from all flocks all over the experimentation period.

Enzyme Linked Immunosorbent Assay (ELISA) ELISA was performed according to the manufacturer instruction (ID-VET) for determining $P$. multocida antibody titer. 


\section{Haemagglutination inhibition (HI) test}

It was carried out according to OIE (14) for the evaluation of immune response against AI.

\section{Challenge test}

a- Challenge with virulent $P$. multocida strains.

This test was done according to (15). Vaccinated birds (30 per each flock) as well as nonvaccinated (15 per each flock) were challenged by inoculation of $0.1 \mathrm{ml}$ of $2 \times 10^{2}$ CFU of $P$. multocida Serotypes 1, 3, and 4 (10 vaccinated and 5 non vaccinated birds for each serotype) via intramuscular route 3 weeks after both first and booster dose vaccination. All birds were observed for 14 days and mortalities were recorded.

\section{b- Challenge with AI H9N2 strain}

This was done according to (16). 30 vaccinated as well as 10 non-vaccinated birds per each flock were challenged by inoculation of $0.1 \mathrm{ml}$ of $\mathrm{AI} 10^{6} \mathrm{EID}_{50}$ strain via intranasal route 3 weeks after first and booster dose of vaccination then cloacal swaps were collected on 1, 3 and 5 days post challenge to check virus shedding and protection obtained.

\section{Results and discussion}

Control of fowl cholera and avian influenza are still subject of interest and usually attract the attention of researchers to know more about diseases, epidemiology and how to control in susceptible birds. Despite the prophylactic measures for protection against both diseases using various vaccines and different vaccination programmes, mortality and losses still occur due to respiratory diseases. Combination of bacterial and viral vaccines has many benefits for the manufacturer as it reduce production costs, save time, effort and simplify the immunization schedule. Also it minimize stress of multiple vaccinations on the animals. Vaccination is still considered one of the major tools for controlling both of the two diseases. Vaccine efficacy depend on many variables, such as the nature, the amount of antigen administrated and the presence of adjuvant to enhance immunogenicity (17).
FC and AI vaccine was prepared using Montanide ISA 206 and evaluated by measuring humeral immune response and vaccination challenge assays against both in this field study.

Assessment of Quality control measures for the prepared inactivated vaccine indicated that, the prepared vaccine was completely sterile, haven't any bacterial or fungal contaminants when tested on specific bacteriologic and fungal media. In addition there was no local, systemic reaction or mortalities were recorded in inoculated chicks, and these denote to the safety of the prepared vaccine.

Regarding the potency of the prepared vaccine, the serological tests carried out on serum samples obtained from vaccinated chickens with the combined FC and AI vaccine revealed that such birds exhibited detectable P. multocida antibodies from the first week post vaccination as shown in Table (1). The ELISA antibody titers increased gradually till reach its maximum level at the $5^{\text {th }}$ week post first vaccination where it records 1247, 1197 and 1226 in case of broiler breeder, broiler and turkey flocks respectively. This is consistent with (18) who reported that the antibody titres significantly increased 3 weeks after primary vaccination. Booster doses caused a rapid shooting in the antibody titer and reached its highest level at the end of $3^{\text {rd }}$ week post boostering. The highest antibody titers were 1832, 1578 and 1801, respectively.

It is clear that all birds showed a secondary response greater than that seen in birds vaccinated once, these findings was in accordance with that recorded by (15) who stated that a significant immunological stimulus had been elicited by the $2^{\text {nd }}$ exposure and (19) who reported that the immune response of secondary immunization was significantly higher than the primary immunization. On the other hand (20) evaluated the immune response induced by several adjuvants included in Pasteurella multocida vaccines and stated that there is no significant decrease of antibody titres was observed between 4 and 8 weeks after vaccination.

The inoculation of booster dose of combined vaccine at the start of $4^{\text {th }}$ week caused a rise of antibodies titer where reached the peak against 
P. multocida at the $3^{\text {rd }}$ week post boostering. From these investigations, it was clear that for longer term protection against $\mathrm{FC}$, the vaccines should be given at two doses, at least three weeks apart.

As regards to the HI test that carried out on serum samples obtained from vaccinated chickens with the prepared combined FC and AI vaccine, it revealed that there was an increase in AI antibodies with titer of $6.4,5.8$ and $6.4 \log _{2}$ when measured at the $3^{\text {rd }}$ week post single dose of vaccination which raised gradually up to its maximum level at the $5^{\text {th }}$ week recording 7.8, 7.2 and 7.6 in broiler breeder, broiler chickens and turkey respectively as shown in Table (2). Meanwhile the inoculation of booster dose after 3 wks caused a rapid rise of antibodies titer where the peak of AI antibody titer was 8.6, 8.0 and $8.2 \log _{2}$ by the $3^{\text {rd }}$ week post boostering respectively. The same results obtained by (21) who determined the efficacy of two oil emulsion (ISA 206, ISA70) HA subunit vaccine derived from $\mathrm{H} 5 \mathrm{~N} 1$ virus.

The same results obtained by (22) who evaluated the quality of oil emulsion AI H9N2 vaccine in-vitro by HI test without boostering. They found that the antibody titer increased till reach its peak $\left(6.24 \log _{2}\right)$ at $5^{\text {th }}$ week post vaccination. On the other hand, (23) evaluated a reverse genetics H5N3 avian influenza virus cell cultured vaccine by single dose and the HI titer reached its peak $\left(6.2 \log _{2}\right)$ at the $4^{\text {th }}$ week. (21) Found that chickens which received one dose of rHA- H5 vaccine had a markedly poor response and priming by two dosages appeared to improve the antibody response. (24) evaluated inactivated H9N2 vaccine with gel-primed and mineral oil- boosted regimen in broiler breeders. They concluded that a single dose regimen of inactivated H9N2 vaccine provided not enough anti body level in the broiler breeder flock and recommended a two doses regimen than single dose. Also stated that a gel-primed and oil- boosted regimen might be an economical and effective vaccine strategy for poultry producers.

Regarding the challenge test, the protection percentages of birds against $P$. multocida strains were 76.6, 70.0 and $80.0 \%$, among broiler breeder, broiler and turkey groups respectively when challenged 3 weeks after single dose, while they were 90.0, 86.6 and $93.3 \%$, among the same groups when challenged 3 weeks after booster dose as shown in Table (3).

The results obtained by (25) who reported that the protection $\%$ in ISA 206 combined FC and ND vaccine was $100 \%$. Also (26) noticed that chickens vaccinated with FC vaccine containing ISA 206 showed 90\% protection. From these data it was clear that the antibody titer was measured with ELISA test was highly correlated with protection against challenge with virulent organisms as reported by (15).

For the protection against AI H9N2 virus, it was $83.3,80.0$ and $86.6 \%$ among the broiler breeder, broiler and turkey bird groups when challenged 3 weeks after single dose as shown in Table (4). These protection percentages were raised up to $93.3,90.0$ and $96.6 \%$ for the same bird groups when challenged 3 weeks post booster of vaccination.

An inactivated ISA $70 \mathrm{H} 9 \mathrm{~N} 2$ vaccine was evaluated by (27) and concluded to this vaccine induced protection $100 \% 3$ weeks post vaccination where the virus isolated from $0 / 7$ cloacal samples collected on 1, 3 and 5 days post challenge. In contrast (23) concluded that ISA 206 adjuvant vaccine provides only $50 \%$ or even less protective efficiency to SPF chickens. Meanwhile (28) recorded that the protection levels were found to increase up to $90 \%$ when the Montanide ISA 70 and Montanide ISA 206 formulations were used.

The findings of this study indicated that the vaccine is valid and has a satisfactory result according to specifications of OIE (14).

\section{Conclusion}

Conclusively, it is very beneficial to apply the inactivated polyvalent Pasteurella multocida and $\mathrm{AI}$ H9N2 vaccine for the protection against both FC and $\mathrm{AI}$ outbreaks as it reduce production costs, for the administrator as it save time, effort and simplify the immunization schedule. Also for the birds, it minimizes stress of multiple vaccinations. 
Table 1: $P$. multocida ELISA mean titer of different bird flocks vaccinated with the prepared FC and AI (H9N2) vaccine post single and booster dose vaccination

\begin{tabular}{|c|c|c|c|c|c|c|c|c|c|}
\hline \multirow{2}{*}{$\begin{array}{l}\text { Type of } \\
\text { Birds }\end{array}$} & \multicolumn{8}{|c|}{ Weeks post vaccination } & \multirow[t]{2}{*}{ Control } \\
\hline & & 1 & 2 & 3 & 4 & 5 & 6 & 7 & \\
\hline \multirow{2}{*}{$\begin{array}{l}\text { Broiler } \\
\text { breeder }\end{array}$} & Single dose & 523 & 841 & 1011 & 1176 & 1247 & 1208 & 1185 & 36 \\
\hline & Booster dose & & & & 1381 & 1566 & 1832 & 1792 & 41 \\
\hline \multirow{2}{*}{ Broiler } & Single dose & 469 & 719 & 904 & 1066 & 1191 & 1174 & 1081 & 39 \\
\hline & Booster dose & & & & 1218 & 1466 & 1578 & 1511 & 38 \\
\hline \multirow{2}{*}{ Turkey } & Single dose & 497 & 819 & 973 & 1118 & 1226 & 1211 & 1172 & 44 \\
\hline & Booster dose & & & & 1341 & 1494 & 1801 & 1716 & 29 \\
\hline
\end{tabular}

Table 2: AI H9N2 HI mean titer of different bird flocks vaccinated with the prepared FC and AI (H9N2) vaccine post single and booster dose vaccination

\begin{tabular}{|c|c|c|c|c|c|c|c|c|c|}
\hline \multirow{2}{*}{\multicolumn{2}{|c|}{ Type of Birds }} & \multicolumn{7}{|c|}{ Weeks post vaccination } & \multirow[t]{2}{*}{ Control } \\
\hline & & 1 & 2 & 3 & 4 & 5 & 6 & 7 & \\
\hline \multirow{4}{*}{$\begin{array}{l}\text { Broiler } \\
\text { breeder } \\
\text { Broiler }\end{array}$} & Single dose & 3.6 & 4.8 & 6.4 & 6.6 & 7.8 & 7.6 & 7.2 & 0.0 \\
\hline & Booster dose & & & & 7.2 & 8.2 & 8.6 & 8.2 & 0.0 \\
\hline & Single dose & 3.2 & 4.0 & 5.8 & 5.8 & 7.2 & 6.8 & 6.2 & 0.0 \\
\hline & Booster dose & & & & 6.8 & 7.4 & 8.0 & 7.6 & 0.0 \\
\hline \multirow[t]{2}{*}{ Turkey } & Single dose & 3.6 & 4.6 & 6.4 & 6.2 & 7.4 & 7.2 & 6.8 & 0.0 \\
\hline & Booster dose & & & & 7.2 & 7.6 & 8.2 & 7.8 & 0.0 \\
\hline
\end{tabular}

Table 3: Protection percentages obtained in birds vaccinated with single and booster doses of the prepared FC and AI vaccine against virulent $P$. multocida strain

\begin{tabular}{|c|c|c|c|c|c|c|c|c|c|}
\hline \multirow{3}{*}{ Type of Bird } & \multicolumn{6}{|c|}{ Challenge 3 weeks post } & \multirow{2}{*}{\multicolumn{3}{|c|}{ Control }} \\
\hline & \multicolumn{3}{|c|}{ Single dose vaccination } & \multicolumn{3}{|c|}{$\begin{array}{l}\text { Booster dose vaccina- } \\
\text { tion }\end{array}$} & & & \\
\hline & Bird No & M. & $\mathrm{P} \%$ & Bird No & M. & $\mathrm{P} \%$ & Bird No & M. & $\mathrm{P} \%$ \\
\hline Broiler breeder & 30 & 7 & 76.6 & 30 & 3 & 90.0 & 15 & 12 & 20.0 \\
\hline Broiler & 30 & 9 & 70.0 & 30 & 4 & 86.6 & 15 & 14 & 07.0 \\
\hline Turkey & 30 & 6 & 80.0 & 30 & 2 & 93.3 & 15 & 13 & 13.4 \\
\hline
\end{tabular}

$\mathrm{M}=$ Mortalities $\mathrm{P} \%=$ protection percent

Table 4: Protection percentages obtained in birds vaccinated with single and booster doses of the prepared FC and AI vaccine against AI H9N2 virus

\begin{tabular}{llllll}
\hline \multirow{2}{*}{ Vaccination } & \multirow{2}{*}{ Type of bird } & \multirow{2}{*}{ ECE No. } & HA & \multicolumn{2}{c}{ Protection \% } \\
\cline { 3 - 5 } & & & Positive & Negative & \\
Single dose & Broiler breeder & 30 & 5 & 25 & 83.3 \\
& Broiler & 30 & 6 & 24 & 80.0 \\
& Turkey & 30 & 4 & 26 & 86.6 \\
\multirow{3}{*}{ Booster dose } & Broiler breeder & 30 & 2 & 28 & 93.3 \\
& Broiler & 30 & 3 & 27 & 90.0 \\
& Turkey & 30 & 1 & 29 & 96.6 \\
\hline
\end{tabular}




\section{Conflict of interest}

The authors declare that they have no conflict of interest.

\section{References}

1. Glisson, J.R., C.L. Hofacre and J.P. Christensen. Fowl cholera. In: Diseases of poultry, Saif YM, Barenes HJ, Glisson JR, Fadly AM, McDougald LR and Swayne DE (Editors). Blackwell Publishing, Ames, Iowa, USA, 2008; 739-58.

2. Swayne, D.E. and D.A. Halvorson. Avian influenza. In: Saif, Y.M., Barnes, H.J., Fadly, A.M., Glisson, J.R., McDougald, L.R., Swayne, D.E. (Eds.). Diseases of Poultry. 11th ed. Iowa State Press, Iowa. 2003; pp. 135-60.

3. Adler, B., D. Bulach, J. Chung, S. Doughty, M. Hunt, K. Rajakumar, M. Serrano, A. Van Zanden, Y. Zhang and C. Ruffolo. Candidate vaccine antigen and genes in Pasteurella multocida. J. Biotech. 1999; 73(2-3): 83-90.

4. Takai, H., Y. Hayakawa, E. Shintani, H. Komae, Y. Yoshida, H. Ide, G. Abe and T. Sawada. The first outbreak of P.multocida. infection in turkeys in Japan. J. Japan Vet. Med. Association, 1994; 47:923-7.

5. Voyles, B.A. Orthomyxoviruses. In: The biology of viruses 2nd Ed. New York, NY: McGraw-Hill, 147. 2002.

6. Alexander, D. J. Should We Change the Definition of Avian Influenza for Eradication Purposes? Avian Diseases. 2003; 47: 976-81.

7. Bano, S., K. Naeem and S.A. Malik. Evaluation of Pathogenic Potential of Avian Influenza Virus Serotype H9N2 in Chickens. Avian Diseases. 2003; 47:817-22.

8. Alexander, D. J. A review of avian influenza in different bird species. Vet. Microbiol. 2000; $74(1-2)$ : 3-13.

9. Orabi A, Hussein A, Saleh A A, El-Magd M A, Munir M. Evolutionary insights into the fusion protein of Newcastle disease virus isolated from vaccinated chickens in 2016 in Egypt, Archives of Virology 2017; 162(10): 3069-79

10. Reddy, G.S.; K. Ananda and V.A. Srinivasan. Performance of oil adjuvant combined vaccine cintaining FMD, Rabies, Pasteurella multocida and Clostridium chauvoei antigens. Indian Veterinary Journal, 2001; 78(11): 990-3.

11. Swayne, D.E.; D.A. Senne and C.W. Beard. Influenza, in: Swayne, D.E.; Glisson, J.R.; Jackwood, M.W.; Pearson, J.E. and Reed, W.M. (Eds), Isolation and identification of avian pathogens:
Kennet Square: American Association of Avian Pathologist. 1998; 150-5.

12. Villegas, P. 1998. Titration of biological suspensions. In: Swayne, D.E. (Ed), A Laboratory Manual for the Isolation and Identification of Avian Pathogens, fourth ed. American Association of Avian Pathologists, Kennett Square, PA, 1998; 248-54.

13. Sarachai, C.; J. Sasipreeyajan, and N. Chansiripornchai. Avian Influenza virus (H5N1) inactivation by Binary Ethylenimine. Thai J. Vet. Med. 2010; 40(1): 41-6.

14. OIE. Manual of Standars of Diagnostic Tests and Vaccines for Terrestrial Animals Safety Test, 2017; chapter, 2.3.4., Avian influenza page no. 446 .

15. Jabbri, A. R. and G.R. Moazeni Jula. Fowl cholera: Evaluation of a Trivalent Pasteurella multocida Vaccine Consisted of Serotypes 1, 3 and 4. Arch. Razi Ins. 2005; 59: 103-11.

16. Kwon, J.S.; H.J. Lee, D.H. Lee, Y.J. Lee, I.P. Mo, S.S. Nahm, M.J. Kim, J.B. Lee, S.Y. Park, I.S. Choi and C.S. Song. Immune response and pathogenesis in immunocompromised chickens in response to infection with the H9N2 low pathogenic avian influenza virus. Virus Research, 2008; 133: 187--94.

17. Stone, D.; M. Brugh, S.R. Hophins, H.W. Yoder and C.W. Peard. Preparation of inactivated oil emulsion vaccines wiyh avian viral or Mycoplasma antigens. Avian Dis., 1978; 22: 666-47.

18. Parvin, M.S., M. P. Siddique and M. T. Islam. Humoral immune response to fowl cholera vaccine in different breeds of commercial birds Bangl. J. Vet. Med. 2011; 9 (2): 127 -31.

19. Iqbal, M.T.; M.H. Haque, S. Sarker, M.A. Islam and K.A. Choudhury. Determination of immune response against alum- precipitated fowl cholera vaccine in the quail, coturnix japonica. Univ. J. Zool. Rajshahi. 2010; 29: 57-60.

20. Belloc, C.; L. Dupuis, S. Deville, H. Aucouturier and A. Laval. Evaluation of safety and immune response induced by several adjuvants included in Pasteurella multocida vaccines in chickens. Revue Méd. Vét., 2008; 159(7): 371-5.

21. Lin, Y. J.; M. C. Deng, S. H. Wu, Y. L. Chen, H. C. Cheng, C. Y. Chang, M. S. Lee, M. S. Chien and C.C. Huang. Baculovirus-Derived He magglutinin Vaccine Protects Chickens from Lethal Homologous Virus H5N1 Challenge. J. Vet. Med. Sci. 2008; 70(11): 1147-52.

22. Rajabi, Z.; H.T. Nasrabadi and A.B. SyofiKhojin. Evaluation the quality of oil-Emulsion 
Avian Influenza subgroup H9N2 vaccines in invitro. Vaccinology, 2010; 2: 22-5.

23. Liu, C.G.; Ming Liu, Fei Liu, Da F Liu, Yun Zhang, Wei Q Pan, Hao Chen, Chun H Wan, En C Sun, Hong $\mathrm{T} \mathrm{Li}$, and Wen $\mathrm{H}$ Xiang. Evaluation of several adjuvants in avian influenza vaccine to chickens and ducks. Virol J.; 2011; 8: 321.

24. Lee, D.H.; J.S. Kwon, H.J. Lee, Y.N. Lee, W. Hur, Y.H. Hong, J.B. Lee, S.Y. Park, I.S. Choi and C.S. Song. Inactivated H9N2 avian influenza virus vaccine with gel-primed and mineral oilboosted regimen could produce improved immune response in broiler breeders. Poultry Science, 2011; 90: $1020-2$.

25. Elham, A. youssef; Eman, A. Hassan; Mervata, A. El-Koffy and A.M. Daoud. Trial for preparation of combined oil inactivated vaccine against Newcastle and Fowl Cholera diseases by using Montanide ISA 206 oil for improving the immune response in chickens. Vet. Med. J. Giza, 2005; 53 (2): 341-52.
26. Hala, A.F.; I.S. Ibrahim, H.G. Fawzy and S.M. Aboul Saoud. Preparation and evaluation of avian cholera oil emulsion vaccine using Montanide ISA 206. Egypt. Vet. Med. Assoc., 2002; 62(2).

27. Jun G. C.; J.L. Youn, J.K. Yong, K.L. Eun, O.M. Jeong, W.S. Haan, H.K. Jae and H.K. Jun. An inactivated vaccine to control the current H9N2 low pathogenic avianinfluenza in Korea. J. Vet. Sci., 2008; 9 (1): 67-74.

28. Dungu, B.; B. Brett, R. Macdonald, S. Deville, L. Dupuis, J. Theron and R.R. Bragg. Study on the efficacy and safety of different antigens and oil formulations of infectious coryza vaccines containing an NAD-independent strain of Avibacterium paragallinarum. Onderstepoort Journal of Veterinary Research, 2009; 76:299-309.

29. Fatma Elzahraa G. AboElkhir, Afaf A. Khedr and Elseedy F R. Identity of Pasteurella multocida and Avian Influenza H9N2 Strains Used in Preparation of a Combined Inactivated Vaccine Using PCR. Global Veterinaria 2005; 14 (4): 535-8. 